\title{
SENTIDOS SOBRE TECNOLOGIA EM EDUCAÇÃO PROFISSIONAL E TECNOLÓGICA: UMA MIRADA SOBRE A POLITECNIA
}

\author{
Raquel Folmer Corrêa \\ Docente do Ensino Básico, Técnico e Tecnológico de Sociologia no Instituto Federal do Rio Grande do \\ Sul-raquel.correa@vacaria.ifrs.edu.br
}

\begin{abstract}
Resumo: $\mathrm{O}$ artigo tem como propósito apresentar uma revisão bibliográfica sobre politecnia. A investigação faz parte de debates que problematizam sentidos sobre tecnologia em diferentes contextos educacionais, em específico, os modos pelos quais a politecnia é abordada na produção científica do campo em Educação Profissional e Tecnológica (EPT) brasileiro atual. O suporte teórico e metodológico é constituído por leituras sobre a perspectiva marxiana de educação, e interlocuções marxistas, em diálogo com posicionamentos críticos da educação Ciência, Tecnologia e Sociedade (CTS) latino-americana. A pesquisa tem enfoque qualitativo, com coleta e análise de dados bibliográficos, e baseada em exame crítico, descrição e apreciação sócio-histórica do material. O levantamento bibliográfico preliminar indica o que se poderia chamar de sentido clássico sobre politecnia: princípio formador necessário à superação da unilateralidade imposta à classe trabalhadora. A leitura realizada permitiu reflexões sobre possibilidades e limites de efetivação de agendas de pesquisas sobre formação humana crítica, civil, laica, integral, integrada e permanente em EPT no Brasil contemporâneo.
\end{abstract}

Palavras-chave: Tecnologia; Politecnia; EPT.

\section{MEANINGS ABOUTTECHNOLOGY IN PROFESSIONAL AND TECHNOLOGICAL EDUCATION: A VIEW AT POLYTECHNICS}

\begin{abstract}
The primary aim is to present a bibliographical review on polytechnics. The enquiry is part of debates that problematize meanings about technology in different educational contexts, specifically, the ways in which polytechnics is approached in the scientific production of the current Brazilian PTE field. The theoretical and methodological support consists of readings on the Marxian perspective on education, and Marxist dialogues, in dialogue with critical positions of Latin American STS education. The research has a qualitative focus, with collection and analysis of bibliographic data, and are based on critical examination, description, and sociohistorical appreciation of the material. The preliminary bibliographic survey indicates what could be called the "classic sense" about polytechnics: a necessary formative principle to overcome the unilaterality imposed on the working class. The reading carried out allowed reflections on the possibilities and limits of carrying out research agendas on critical, civil, lay, integral, integrated, and permanent human formation in PTE in contemporary Brazil. Keywords: Technology; Polytechnics; PTE.
\end{abstract}




\section{Introdução}

A escola socialista só é concebível em determinadas condições sociais, pois o que a torna socialista não é o fato de ser liderada pelos socialistas, mas sim que suas metas correspondam às necessidades da sociedade socialista (KRUPSKAYA, 2017, p. 76).

Examinar relações entre tecnologia, trabalho e educação não se constitui como novidade. Estudos e pesquisas em Educação Profissional e Tecnológica (EPT) no Brasil, têm demonstrado tais ligações sob diversos referenciais que abordam desde educação básica e superior, políticas públicas, formação docente, até interseccionalidades entre gênero, raça/etnia e classes sociais. É possível assumir, mesmo que provisoriamente, que a unidade em toda essa diversidade se encontre na perspectiva do trabalho como princípio educativo. E, estando a categoria trabalho vinculada sobremaneira à categoria tecnologia, aproximações com referenciais que discutem implicações da tecnologia na educação são pertinentes.

Investigações latino-americanas contemporâneas que relacionam de modo interdisciplinar ciência, tecnologia e sociedade (CTS), o chamado Enfoque CTS, têm apresentado resultados interessantes (necessários, embora não suficientes) no que diz respeito à identificação e problematização de sentidos sobre tecnologia que circulam em diferentes contextos educacionais. Análises críticas às ideias de neutralidade, essencialidade e autonomia da tecnologia, por exemplo, estão presentes nesse enfoque, aqui particularizado como educação CTS.

A relevância de buscar intensificar aproximações dialógicas entre o campo da educação CTS latino-americana, e referenciais em EPT, está em contribuir com a produção de conhecimentos contextualizados sobre sentidos que o trabalho assume como princípio educativo sociotécnico. Ou seja, trabalho enquanto categoria que explicita que a sociedade é tão tecnologicamente construída quanto a tecnologia é socialmente desenvolvida. Proposição essa, que tem como ponto de partida o exame da politecnia, tendo em vista que tal categoria permite analisar trabalho, educação e tecnologia conjuntamente.

Essa iniciativa não pretende esgotar o debate, pois, antes, busca expandir entendimentos sobre as múltiplas e complexas relações entre tecnologia e sociedade, especificamente em processos educacionais voltados à emancipação humana e vinculados a 
perspectivas de transformação social efetiva. Para isso, o texto está dividido do seguinte modo. Inicialmente, são consideradas as orientações teóricas utilizadas. Em seguida, são apresentados os procedimentos metodológicos que guiam a investigação e, posteriormente, os resultados sobre politecnia são discutidos. Finalmente, são encaminhadas algumas considerações sobre o estudo realizado.

\section{Fundamentação Teórica}

O suporte teórico-metodológico que guia a investigação é constituído por leituras sobre a perspectiva marxiana de educação, e interlocuções marxistas, em diálogo com posicionamentos críticos no campo da educação CTS latino-americana ${ }^{1}$. Tendo em vista a organização do texto, os procedimentos metodológicos são apresentados logo a seguir. Contudo, em fidelidade ao referencial utilizado, é importante destacar, como faz Netto (2011), que em Marx, as elaborações teóricas e as formulações metodológicas mantêm uma associação cuidadosa, algo mesmo como uma unidade. De modo que, nesse momento, a educação CTS, e suas interlocuções em EPT, são abordadas tanto como referencial teórico na análise da realidade concreta quanto constituintes de princípios metodológicos de apreensão desse real. A ideia é pontuar e demarcar as perspectivas segundo as quais os sentidos sobre politecnia são aqui investigados.

Antes disso, é importante destacar brevemente a ideia de tecnologia que guia a pesquisa, as filiações teóricas dentro da educação CTS e a articulação dessas com estudos em EPT. Nesse sentido, a perspectiva teórico-metodológica que abarca tais interlocuções, diz respeito às análises estruturais realizadas por Feenberg (2003) no contexto da Teoria Crítica da Tecnologia (TCT), herdeira da Escola de Frankfurt e, portanto, de viés marxista.

Para Feenberg (2003), a TCT é desenvolvida com a problematização de posicionamentos ingênuos (ou limitados) frente a nossas relações com a tecnologia. Posicionamentos esses nos quais as ideias de autonomia e neutralidade da tecnologia estariam combinadas de modo a ser possível verificar visões do tipo determinista, instrumental e substantivista nessas relações. A crítica da TCT a tais posicionamentos, considera a possibilidade de controle humano da tecnologia e percebe essa como carregada de valores socialmente específicos, e não como neutra. 
Para o autor,

A teoria crítica da tecnologia sustenta que os seres humanos não precisam esperar um Deus para mudar a sua sociedade tecnológica num lugar melhor para viver. A teoria crítica reconhece as conseqüências catastróficas do desenvolvimento tecnológico ressaltadas pelo substantivismo, mas ainda vê uma promessa de maior liberdade na tecnologia. O problema não está na tecnologia como tal, senão em nosso fracasso até agora em inventar instituições apropriadas para exercer o controle humano dela (FEENBERG, 2003 p. 09).

A TCT possibilita pensar em tais escolhas, em maneiras de submetê-las a controles mais democráticos, de modo que seja possível a intervenção democrática na tecnologia.Na atualidade, a tecnologia carregaria valores decorrentes de sua vinculação com o capitalismo. Os valores e interesses dos sujeitos, no caso as classes dominantes, influenciariam no desenho, nas decisões e nos procedimentos tecnológicos. A tecnologia não seria um mero instrumento neutro. Tampouco determinaria apenas um modo de vida, pois que consideraria possibilidades de diferentes estilos de vida distintos da mediação tecnológica (FEENBERG, 2003).

Do ponto de vista da marcação ideológica, a TCT se aproxima de formulações de Álvaro Vieira Pinto sobre o conceito de tecnologia.

Toda tecnologia, contendo necessariamente o sentido, já indicado, de logos da técnica, transporta inevitavelmente um conteúdo ideológico. Consiste numa determinada acepção do significado e do valor das ações humanas, do modo social de realizarem-se, das relações do trabalhador com o produto ou o ato acabado, e sobretudo envolve a ligação entre o técnico, em seu papel de fabricante de um bem ou autor de um empreendimento, e o destino dado àquilo que cria. A técnica representa o aspecto qualitativo de um ato humano necessariamente inserido no contexto social que a solicita, a possibilita e lhe dá aplicação (PINTO, 2005, p. 320321).

Definição que, ao explicitar a relação entre técnica e classe trabalhadora, colabora com a compreensão do caráter social que a tecnologia pode assumir enquanto realização humana contextualizada sócio-historicamente.

Feenberg (2003) e Pinto (2005), leitores de Marx, estão em interlocução com a educação CTS latino-americana, pois, além de serem autores com os quais se dialoga nesse campo, compartilham a importância dos contextos nos quais processos que dizem respeito a temas em ciência e tecnologia (ou, $C \& T$ ) se estabelecem. Pinto creditava importância às juventudes, que deveriam ter condições (intelectuais) de dominar tecnologias cada vez mais 
elaboradas. Feenberg propõe que a TCT pode contribuir para se visualizar que as inovações tecnológicas não são como um destino determinado, mas como oportunidades para aperfeiçoar os processos educacionais (CORRÊA, 2016).

Sob tais filiações teóricas, Linsingen (2007) e Nascimento e Linsingen (2006) também

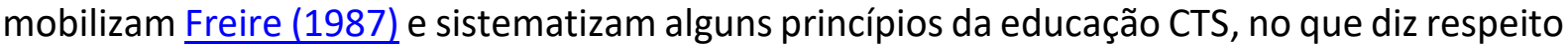
à preocupação com uma abordagem educacional que seja contextualizada, que problematize a noção de transferência de conhecimentos, que esteja em sintonia com os aspectos sociais e que seja comprometida em termos curriculares. Como exemplo, as seguintes questões tornam-se relevantes: o que se ensina, ou não, e por quê? Como ensinar o que é importante para um sujeito em uma situação específica? Como mobilizar para a emancipação e a autonomia? Para quem e onde se fala?

Como campo interdisciplinar e complexo, as análises em educação CTS são diversas e verificam desde implicações sociais da ciência e da tecnologia na educação, formação docente, política científica e tecnológica, relações de gênero e étnico-raciais no âmbito da ciência e da tecnologia, até formas de socialização (divulgação) de conhecimentos científicos e tecnológicos (CORRÊA, 2016), por exemplo.

Em específico, o campo da educação CTS latino-americana, em suas contradições e diversidades teórico-metodológicas, tem considerado aspectos filosóficos, antropológicos, políticos, econômicos e sociológicos da ciência e da tecnologia. A ideia a que aqui se filia, a TCT, diz respeito à que a educação CTS compreenda diferentes condicionamentos estruturais nas decisões e nos processos científicos e tecnológicos, assumidos como práticas sociais não neutras e dependentes de contextos sócio-históricos. E, que a partir disso, seja possível a busca por realidades possíveis para que sujeitos envolvidos em processos educacionais possam tomar decisões informadas e críticas em assuntos científicos e tecnológicos (CASSIANI; LINSINGEN, 2010).

Portanto, desde a identificação de visões naturalizadas e essencialistas em relação à tecnologia, posicionamentos críticos são assumidos na educação CTS. Com isso, há o entendimento de que perspectivas voltadas a uma racionalidade técnica e focadas nos sistemas de produção, não são exclusividade de estudos em EPT. Esse campo apresenta espaços dialógicos para abordagens sociotécnicas, como o referencial aqui utilizado. 0 
destaque é tanto para a compreensão da complexidade e diversidade de abordagens dentro de EPT quanto para o cuidado em não a assumir de modo genérico e simplificado. A partir desse olhar, sentidos sobre politecnia são examinados em produções científicas em EPT no Brasil atual conforme detalhado nos procedimentos metodológicos a seguir.

\section{Procedimentos Metodológicos}

O presente artigo é um recorte de uma pesquisa ampla que busca caracterizar e problematizar sentidos sobre tecnologia na produção científica em EPT no Brasil da atualidade. Tal investigação tem como corpus de análise resumos e palavras-chave ${ }^{2}$ de artigos publicados na Revista Brasileira da Educação Profissional e Tecnológica (RBEPT), nos últimos cinco anos: desde o volume 01 , número 12 , do ano de 2017, até o volume 01 , número 20 , do ano de 2021. Essa amostra temporal condiz com o período de consolidação do periódico.

Entretanto, antes da análise dos dados secundários coletados em resumos de cerca de 200 artigos na RBEPT no período citado, é necessário situar teoricamente as categorias que são estudadas. Quais sejam, politecnia, determinismo tecnológico e tecnologia social, foram categorias escolhidas por contemplarem sentidos sobre tecnologia de modo abrangente e contextualizado com a atualidade sócio-histórica latino-americana. Tal discussão teórica compõe o momento atual da investigação e, dada a relevância histórica e conceitual da categoria politecnia, ela inicia as problematizações e constitui o foco desse artigo.

Nesse primeiro momento, a categoria é examinada desde a perspectiva marxiana, especificamente a compilada em Textos sobre Educação e Ensino (MARX, ENGELS, 2004) ${ }^{3}$. Interlocuções marxianas com produções marxistas que articulam reflexões em torno do trabalho e da educação, serão consideradas no contexto maior da investigação. Do mesmo modo, também serão discutidos os textos "Ensaios sobre a escola politécnica", de Moisey M. Pistrak, "A construção da pedagogia socialista", de Nadezhda K. Krupskaya, e "Rumo ao politecnismo", de Viktor N. Shulgin (com consideração das contradições e disputas entres tais autores e autoras). Interlocutores e interlocutoras do Brasil e de outras regiões serão mobilizados/as nessas articulações ${ }^{4}$.

Portanto, a pesquisa tem caráter qualitativo, com coleta de dados bibliográficos e análise baseada em leitura crítica, descrição e apreciação sócio-histórica do material. Esse 
enfoque qualitativo corresponde a um modo de compreender e analisar a realidade qualificado como crítico-participativo com visão histórico-estrutural (TRIVIÑOS, 1987). Procedimento que, de maneira geral, corresponde a uma técnica de pesquisa de intervenção sociológica (THIOLLENT, 1985), na qual os dados coletados e analisados passam por três momentos (de inspiração dialética), aqui brevemente sumariados: (i) observação das qualidades gerais da realidade (caos concreto), (ii) estabelecimento das relações sóciohistóricas do fenômeno (instância abstrata) e (iii) caracterização de aspectos essenciais do fenômeno (concreto pensado).

A intenção é que, desde a concretude dos resumos da RBEPT, sentidos sobre tecnologia (politecnia, nesse momento) sejam examinados sob uma perspectiva teórica marxiana e marxista que permita um retorno contextualizado a esses sentidos, considerando sócio-historicamente suas complexidades e contradições. De modo que formulações teóricas e metodológicas são (e estão) indissociadas na busca por “(...) apreender não a aparência ou a forma dada ao objeto, mas a sua essência, a sua estrutura e a sua dinâmica" (NETTO, 2011, p. 25). Caminho esse, que não permite simplificações reducionistas, por isso a atenção constante na análise bibliográfica até aqui empreendida, como verificado a seguir.

\section{Resultados e Discussões}

Investigações que proponham analisar relações entre educação e trabalho têm, na politecnia, um conceito incontornável. Mesmo assim, a literatura mostra que desvios e atalhos não são raros, e que as complexidades e contradições, no que diz respeito à formação humana, fomentam debates para além de contextos escolares. Entretanto, compreender sentidos sobre politecnia em processos educacionais, remete à busca sócio-histórica de desenvolvimento do conceito, tendo em vista suas potencialidades emancipatórias no Brasil contemporâneo.

Antes desse resgate, e tendo em vista o foco em processos educacionais, é importante uma posição quanto certa controvérsia em relação a denominações, pois educação tecnológica e educação politécnica são expressões encontradas no debate. Conforme Saviani (2003), educação tecnológica se refere a uma apropriação do termo pelo discurso burguês hegemônico, enquanto a educação politécnica representa que "a concepção de politecnia foi 
preservada na tradição socialista, sendo uma das maneiras de demarcar esta visão educativa em relação àquela correspondente à concepção dominante" (SAVIANI, 2003, p. 146). Portanto, nesse texto, a politecnia tem expressão correspondente na educação politécnica.

Ao abordar as origens do conceito de politecnia, Manacorda (2010, 2013), especifica trabalhos de Marx ${ }^{5}$ de meados do século XIX, mas também ressalta o envolvimento posterior de Gramsci (integração entre educação, trabalho e cultura na escola unitária) e Lênin (função econômica e social da educação para a construção da sociedade comunista). Há destaque para as pesquisas de Krupskaya, que havia estudado a questão para revisar a educação na Rússia (desde o ano de 1917) e encontrado referências à educação geral politécnica em "Pestalozzi, Owen, Bellers, Lavoisier e outros queriam que as crianças desde tenra idade participassem do trabalho produtivo. Esta participação dá consciência da sua utilidade, constrói uma relação séria perante a vida" (KRUPSKAYA, 2017, p. 57).

Para além dos desenvolvimentos posteriores a Marx, é importante indicar dois aspectos: (i) na origem, no contexto em que Marx começou a refletir sobre politecnia, a escola ainda não era uma instituição democratizada, mas restrita a classes privilegiadas (SAVIANI, 1987; MOURA; LIMA FILHO; SILVA, 2015) e (ii) Marx não tinha um foco específico na educação escolar, mas forneceu elementos para a crítica da influência do capitalismo nesse âmbito de formação. “(...) A temática pedagógica é, de fato, tratada de maneira ocasional em seus aspectos específicos, mas que, acima de tudo, está colocada organicamente no contexto de uma crítica rigorosa das relações sociais" (MANACORDA, 2010, p. 33).

Um tratamento mais específico à questão, é encontrado no texto do ano de 1866, Instruções para os delegados do Conselho Geral Provisório (daqui para frente, apenas Instruções), no qual Marx e Engels definem o que entendem por educação.

Por educação entendemos três coisas: Educação intelectual. Educação corporal, tal como a que se consegue com os exercícios de ginástica e militares. Educação tecnológica, que recolhe os princípios gerais e de caráter científico de todo o processo de produção e, ao mesmo tempo, inicia as crianças e os adolescentes no manejo de ferramentas elementares dos diversos ramos industriais (MARX; ENGELS, 2004, p. 68).

Ideia que não faz parte apenas do "Instruções", mas que, em sua essência, conforme Moura; Lima Filho e Silva (2015), está presente em discussões em textos de "O capital", "A ideologia alemã", "Crítica ao Programa de Gotha" e "Manifesto comunista". 
Na formulação original do "Instruções", é possível verificar a indissociabilidade da educação intelectual, corporal e tecnológica. A politecnia surge na sequência, quando os autores indicam a finalidade de sua proposta. "Esta combinação de trabalho produtivo pago com a educação intelectual, os exercícios corporais e a formação politécnica elevará a classe operária acima dos níveis das classes burguesa e aristocrática" (MARX; ENGELS, 2004, p. 60).

Entretanto, comentadores divergem (Mario Manacorda e Paolo Nosella) sobre o uso dos termos tecnologia e politecnia nessas definições. Nesse momento, no qual se explora um chamado sentido clássico de politecnia, essa controvérsia não é abarcada (Marx usa tecnologia e politecnia), de modo que a perspectiva de Saviani (2003), como demonstrado em momento anterior do texto, é assumida, qual seja, de que se trata de união de formação intelectual e trabalho produtivo. No decorrer da investigação mais ampla as controvérsias citadas serão problematizadas.

Para além desse debate, Moura, Lima Filho e Silva (2015), lembram que Marx defende a educação como formação humana integral para todas as crianças e jovens, independentemente do gênero. É importante pontuar aqui que Marx e Engels (2004), ao integrarem educação e trabalho, consideravam, também, uma regulação do trabalho infantil (redução da jornada e proibição de trabalho noturno) tendo em vista a saúde física e intelectual desses. No "Instruções", ao fazer uma crítica ao emprego fabril de crianças e adolescentes, Marx e Engels (2004, p. 68) afirmam que "a sociedade não pode permitir que pais e patrões empreguem, no trabalho, crianças e adolescentes, a menos que se combine este trabalho produtivo com a educação". E essa preocupação vinha da percepção de que haveria uma tendência da indústria moderna para incorporar o trabalho de crianças e jovens (CORRÊA, 2016).

Portanto, como formação humana, a politecnia trata de uma concepção marxiana de educação segundo a qual o ser humano deve ser integralmente desenvolvido em suas potencialidades (princípio da omnilateralidade) (MANACORDA, 2010). Em Marx (1988), esse propósito educacional apresentaria as condições necessárias à formação de seres genéricos e universalizados, de modo que a razão da existência da classe trabalhadora não poderia ser restrita às condições naturais e às possibilidades de produção material (MANACORDA, 2010; SILVA, 2008). 
Aqui, o princípio educativo do trabalho visaria que a classe trabalhadora tivesse condições de superar perspectivas reducionistas e utilitaristas do trabalho dentro de um processo coletivo "organizado, de busca prática de transformação das relações sociais desumanizadoras e, portanto, deseducativas" (FRIGOTTO, 1999, p. 8). Esse desenvolvimento ocorreria através de um processo educacional de totalidade, que proporcionaria formação científica (capacitação técnica), política e cultural geral (estética), tendo em vista a libertação do ser humano das condições de opressão e exploração.

Concepção que também pode ser debatida por meio dos escritos de Shulgin (2013), sobre politecnismo, quando esse autor indica que,

\footnotetext{
Não se trata, pois, de uma continuação da máquina, nem da preparação de um "parafuso" para ela. Não. Mas da preparação do seu proprietário, o inventor, o criador. A máquina, especialmente em uma era de transição, ficará cada vez mais a serviço do homem. Desde esse ponto de vista deve ser reconstruída também a preparação do trabalhador (SHULGIN, 2013, p. 213).
}

Em Marx e Engels, a politecnia seria uma base formadora necessária à superação da unilateralidade em que a classe trabalhadora estaria mantida, em função da formação voltada exclusivamente para a sua capacitação produtiva (MANACORDA, 2010; SILVA, 2008). Essa unilateralidade se caracterizaria por uma concepção capitalista na qual os sujeitos precisariam atualizar suas habilidades técnicas e produtivas sempre que ocorressem inovações nas formas de produção, mas sem alterar as relações de produção (MARX, 1988). Assim, a unilateralização seria o oposto da universalização defendida por Marx e Engels (MANACORDA, 2010).

Mesmo que Marx não tenha detalhado a operacionalização da união entre educação e trabalho em sua proposta para uma escola pautada nos pressupostos socialistas, lembremos que ela foi posteriormente pensada e planejada em plano concreto, como aponta Pistrak.

Para nós (...) é absolutamente indubitável que a escola politécnica é uma escola do presente, que é preciso construí-la agora e que aqueles que argumentam que a escola politécnica se refere apenas ao futuro, na verdade, continuam tendo uma ideia conservadora da escola politécnica (...) (PISTRAK, 2015, p. 26).

Ainda com base nessa realização concreta, Kuenzer (2006, 2013) destaca que a educação politécnica se refere à integração com vistas à emancipação. A ideia seria integrar trabalho, cultura e ciência; proporcionar o domínio intelectual da técnica e articular: teoria e prática, parte e totalidade, disciplinaridade e transdisciplinaridade. O ensino politécnico 
visaria promover, portanto, aprendizagem com significado e assegurar a participação de estudantes na sistematização dos conhecimentos (ORRÊA, 2016).

Em relação ao ensino politécnico, Rodrigues (2008) descreve que as ideias centrais seriam: (i) educação pública, gratuita, obrigatória e única para todas as crianças e jovens, (ii) combinação de educação (intelectual, corporal e tecnológica) com a produção material para superar o distanciamento entre essas atividades, (iii) formação omnilateral (multilateral, integral) da personalidade e, (iv) integração recíproca da escola à sociedade com o propósito de superar o estranhamento entre as práticas educativas e as demais práticas sociais.

Portanto, no que diz respeito à educação e ensino, um modo sintético de apreensão da politecnia no Brasil se refere às dimensões infraestrutural (reapropriação do domínio do trabalho), socialista (ruptura com a educação estritamente profissionalizante) e pedagógica (promoção de práticas pedagógicas concretas) (RODRIGUES, 2008). Dimensões nas quais a politecnia não prevê uma classe trabalhadora polivalente, antes, considera o domínio dos fundamentos científicos das diferentes técnicas que caracterizam o processo de trabalho

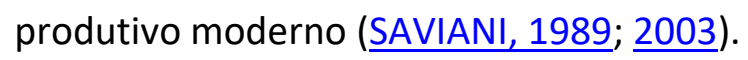

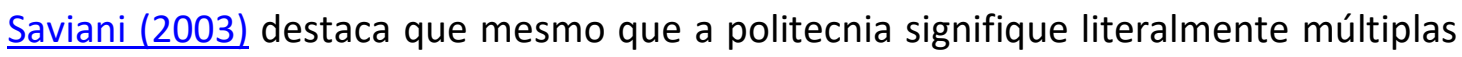
técnicas, esse conceito não se refere à totalidade das diferentes técnicas fragmentadas, autonomamente consideradas. "Se a politecnia fosse o conjunto da totalidade das técnicas disponíveis, haveria uma relação sempre incompleta, sempre sujeita a acréscimo" (SAVIANI,

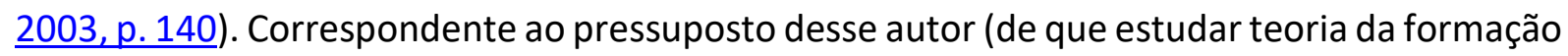
humana consistiria em apreender concepções de homem, sociedade e educação em Marx e Gramsci), a ideia aqui é justamente que a classe trabalhadora possa desenvolver diversas modalidades de trabalho com a compreensão da sua natureza e da sua essência.

Tendo em vista a centralidade do trabalho, em Marx o destaque é que na politecnia não existe trabalho manual puro e nem trabalho intelectual puro, sendo que "todo trabalho humano envolve a concomitância do exercício dos membros, das mãos, e do exercício mental, intelectual. Isso está na própria origem do entendimento da realidade humana como constituída pelo trabalho" (SAVIANI, 2003, p. 138). O que remete à perspectiva de omnilateralidade. 
Portanto, em resumo, há a percepção de um sentido geral da politecnia no qual, antes do mercado de trabalho, o ser humano seria o foco central. Especificamente, haveria a busca por uma formação humana integral na qual a classe trabalhadora pudesse atuar no cenário político e desfrutar do patrimônio cultural produzido pela humanidade (NODRIGUES, 2008). Formação humana baseada nos eixos da formação intelectual, corporal e tecnológica, tendo em vista o domínio de conhecimentos necessários à produção e reprodução de sua existência por meio do trabalho (MOURA; LIMA FILHO; SILVA, 2015).

Esse chamado sentido clássico de politecnia identificado, e aqui sumariado, não ignora as controvérsias em torno das denominações mais pertinentes em relação à tecnologia. Entretanto, ele permite, por sua abertura, problematizar limites dos três eixos de formação humana discutidos. São essas fragilidades, e suas potencialidades, que conduzem ao seguimento da presente pesquisa, como encaminhado a seguir.

\section{Considerações Finais}

O levantamento bibliográfico sobre sentidos da categoria politecnia no viés marxiano, indicou a necessidade de uma imersão maior na literatura, pois as interlocuções marxistas se mostram necessárias a um entendimento aprofundado, mesmo que sem pretensão de esgotar o debate. O aqui chamado sentido clássico, baseado nos eixos intelectual, físico e politécnico, mostra limitações. Por isso, pode, e deve, ser problematizado, tendo em vista as atualizações das discussões que dizem respeito a alterações nos processos produtivos, as novas socializações em nossas relações com a tecnologia e, fundamentalmente, as formas de apropriação do termo no contexto educacional brasileiro atual.

Cenário no qual não é possível ignorar a desvalorização de uma educação laica e crítica ao sistema vigente. Com desmonte de políticas que sustentam direitos sociais em geral, e mobilização constante de setores da sociedade contra a educação formal, inclusive com a propagação de discursos de ódio, principalmente para a educação pública e todos os sujeitos que estão envolvidos com ela. Por isso é tão relevante a busca por aprofundar conhecimentos sobre a politecnia, pois ela guarda possibilidades de perspectivas emancipatórias relevantes em um contexto autoritário e totalitário como o que é experenciado diariamente já há algum tempo. 
Marx e Engels, ainda que não tratem especificamente sobre educação e ensino, mostram como na sociedade capitalista a educação reproduz a ideologia dominante também em níveis técnicos e produtivos. Contudo, há um anúncio de possibilidades de transformação. No texto "Teses sobre Feuerbach", Marx indica que "a coincidência da mudança das circunstâncias com a da atividade humana, ou mudança dos próprios homens, pode ser concebida e entendida racionalmente como prática revolucionária" (Marx e Engels, 2004, p. 35). Não há aqui uma perspectiva salvacionista, mas de entendimento das contradições, de desenvolvimento da consciência e de mobilização para a luta (batalha das ideias).

Ter como ponto de partida um sentido clássico de politecnia como princípio formador necessário à superação da unilateralidade imposta à classe trabalhadora, não fixa um destino, antes, aponta caminhos diversos que tem unidade na ideia de dignidade humana. Omnilateralidade possível, também, desde identificações do caráter social da técnica, da educação revolucionária politécnica e do fundamento sociotécnico do trabalho. Como lembra a pedagoga da epígrafe, os processos educacionais socialistas são como guias em potencial, não determinações (KRUPSKAYA, 2017).

Guias, ou caminhos, já anteriormente explicitados por Marx (1982) ao apresentar sua crítica da economia política, na qual aponta como (...) a humanidade coloca sempre a si mesma apenas as tarefas que pode resolver, pois que, a uma consideração mais rigorosa, se achará sempre que a própria tarefa só aparece onde já existem, ou pelo menos estão no processo de se formar, as condições materiais de sua resolução (MARX, 1982 p. 531).

Assim, a compreensão das contradições nas relações entre trabalho, educação e tecnologia se refere tanto à produção de conhecimentos socialmente referenciados (sensíveis às diversidades religiosas, étnico-raciais e de gênero, por exemplo), quanto a possibilidades de efetivação de agendas de pesquisas sobre formação humana crítica, civil, laica, integral, integrada e permanente em diferentes níveis e modalidades de EPT (Pós-Graduação, Ensino Médio Integrado e EJA EPT), tendo em vista transformações sociais estruturais no contexto brasileiro contemporâneo. 


\section{Referências}

CASSIANI, Suzani; LINSINGEN, Irlan von. Educação CTS em perspectiva discursiva: contribuições dos Estudos Sociais da Ciência e da Tecnologia. Redes, Buenos Aires. V. 16, № 31, dezembro de 2010.

CORRÊA, Raquel Folmer. Tecnologias sociais e educação: possibilidades e limites de transformação de sentidos. 2016. Tese (Doutorado em Educação Científica e Tecnológica) - UFSC, Florianópolis, 2016.

FEENBERG, Andrew. O que é a Filosofia da Tecnologia? (2003). Disponível em: http://www.sfu.ca/ andrewf/. Acesso em: 20 out. 2019.

FREIRE, Paulo. Pedagogia do oprimido. Rio de Janeiro: Paz e Terra, 1987.

FRIGOTTO, Gaudêncio. Educação e a crise do capitalismo real. São Paulo: Cortez, 1999.

KRUPSKAYA, Nadezhda Konstantinovna. A construção da pedagogia socialista. São Paulo: Expressão Popular, 2017.

KUENZER, Acácia. A gestão democrática da Educação Profissional: desafios para sua construção. In: BRASIL. Ministério da Educação. Secretaria de Educação a Distância. Ensino Médio Integrado à Educação profissional. 2006. Brasília: MEC, 2006.

KUENZER, Acácia. Dilemas e sentidos atuais do ensino médio e da educação profissional (painel). In: Seminário Internacional de educação do RS: concepções e sentidos da educação. UFRGS, SEDUC/RS. Porto Alegre, 2013.

LINSINGEN, Irlan von. Perspectiva educacional CTS: aspectos de um campo em consolidação na América Latina. Ciência \& Ensino, vol. 1, número especial, novembro de 2007.

MANACORDA, Mario. A. Marx e a pedagogia moderna. Campinas: Alínea, 2010.

MANACORDA, Mario. O princípio educativo em Gramsci. Americanismo e conformismo. Campinas: Alínea, 2013.

MARX, Karl. Manuscritos econômico-filosóficos e outros textos escolhidos. Vol. II. São Paulo: Nova Cultural, 1988.

MARX, Karl. Para a crítica da economia política. In: MARX, Karl; ENGELS, Friedrich. Obras escolhidas. Lisboa: Avante, 1982.

MARX, Karl; ENGELS, Friedrich. Textos sobre Educação e Ensino. São Paulo: Centauro, 2004.

MOURA, Dante Henrique; LIMA FILHO, Domingos Leite; SILVA, Mônica Ribeiro. Politecnia e formação integrada: confrontos conceituais, projetos políticos e contradições históricas da educação brasileira. Revista Brasileira de Educação, v. 20, 2015.

NASCIMENTO, Tatiana; LINSINGEN, Irlan von. Articulações entre o enfoque CTS e a pedagogia de Paulo Freire como base para o Ensino de Ciências. In: Revista Convergencia (Toluca), v. 13, n. 42, 2006.

NETTO, José Paulo. Introdução ao estudo do método de Marx. São Paulo: Expressão popular, 2011. PINTO, Álvaro Vieira. O conceito de Tecnologia. (Vol. 1) Rio de janeiro: Contraponto, 2005. PISTRAK, Moisey. M. Ensaios sobre a escola politécnica. São Paulo: Expressão popular, 2015. RODRIGUES, José. Educação Politécnica. In: PEREIRA, Isabel Brasil; LIMA, Júlio César. (Orgs.). Dicionário da Educação Profissional em Saúde. Rio de Janeiro: EPSJV, 2008. 
SAVIANI, Dermeval. Escola e democracia. Campinas: Cortez, 1987.

SAVIANI, Dermeval. Sobre a Concepção de Politecnia. Rio de Janeiro: Fundação Oswaldo Cruz, 1989.

SAVIANI, Dermeval. O Choque teórico da politecnia. Trabalho, Educação e Saúde, vol. 1, 2003.

SHULGIN, Viktor Nikholaevich. Rumo ao politecnismo. Artigos e conferências. São Paulo: Expressão popular, 2013.

SILVA, Adnilson. Politecnia versus alienação: contribuições conceituais para o estudo sobre a ofensiva capitalista na educação. (2008). In: Jornada do HISTEDBR. Anais da VIII Jornada do HISTEDBR.

Campinas: FE/UNICAMP: HISTEDBR, 2008. Disponível em:

http://www.histedbr.fae.unicamp.br/acer histedbr/iornada/iornada8/resumos/Adnilson\%20Silva\%2 0(R).doc. Acesso em: 20 out 2020.

THIOLLENT, Michel. Crítica metodológica, investigação social e enquete operária. São Paulo: Polis; 1985.

TRIVIÑOS, Augusto. Introdução à Pesquisa em Ciências Sociais. A Pesquisa Qualitativa em Educação. São Paulo: Atlas, 1987.

\footnotetext{
${ }^{1}$ Aqui, a educação CTS é especificada. Entretanto, no contexto amplo da investigação, há contextualização dos estudos CTS, de modo geral, e de seu desenvolvimento histórico, que desde meados dos anos 1960 contribuem de diversas maneiras para a problematização da natureza do conhecimento científico e tecnológico e de suas implicações sociais, culturais e econômicas.

${ }^{2}$ Disponíveis online no site da revista em: http://www2.ifrn.edu.br/ojs/index.php/RBEPT/issue/archive

${ }^{3}$ Reunião de textos nos quais temas como divisão do trabalho e formação humana no capitalismo ajudam a compreender argumentações (não lineares nem conclusivas) desenvolvidas pelos autores.

${ }^{4}$ Por exemplo: Acácia Kuenzer, Antonio Gramsci, Dermeval Saviani, Gaudêncio Frigotto, Lucília Machado, Mario Manacorda e Paolo Nosella, entre outros/as.

${ }^{5}$ Não está aqui descrito, mas as contribuições de Engels são consideradas nessas construções teóricas e políticas.
} 